\title{
A practice of information processing by rearranging matrix of Jacques Bertin \\ - application of diagram in environmental color workshop -
}

\author{
Qifan HUANG ${ }^{\mathrm{a}, *}$, Akiyo KOBAYASHI ${ }^{\mathrm{b}}$ \\ a Guangzhou Academy of Fine Arts,26267675@qq.com \\ ${ }^{b}$ Musashino Art University, kobayasi@musabi.ac.jp \\ * Corresponding author
}

Keywords: Diagram, Matrix, Visual Variables, Environmental Color Workshop, Color Perception Experience

\begin{abstract}
:
The goal of this research is to apply diagrams to environmental color studies. The experience of environmental color is not only visual experience, but also the relationship of the color and the form of the object, the material, the place, the human perception experience. Diagrams records these factors along with the human perception experiences. These diagrams make it possible to study and analyze environmental color more deeply and more easily. In this paper, we first reviewed the "case studies of environmental color workshops" and "theory of information processing by rearranging matrix of Jacques Bertin" which are related to this research. Next, we conducted an environmental color workshop and evaluated the application of diagrams at workshop by students and experts (design teachers and designers). As a result, we confirmed that the diagrams proposed by us are effective for the environmental color workshop. In particular, it was confirmed that these diagrams are effective for group discussion (analysis).
\end{abstract}

The workshop was held at the South China University of Technology (Guangzhou, China) on October 14 - October 17 , 2016 (Figure.1). The participants were 5 students. First, students walked along a path near the natural lake in the campus and recorded the observed color objects and their perception experiences. Next, the students (A, B, C, D, E) entered the observation results into the matrix type diagram (a) (Figure.2). In diagram (a), the colors observed by each student were displayed on the left side of the observation route, and the photographs of the color objects, the perception experiences on the color objects, and the landscape photographs of the observation place were arranged on the right side of the observation route. Next, according to Jacques Bertin's theory (visual variables and rearrangement of the matrix), diagram (a) was transformed into diagram (b) (Figure.3) and group discussion and information analysis were carried out. In diagram (b), color objects are represented as "rows", and various attributes of color objects as "columns". The attributes of color objects are the keywords extracted from the "perception experiences for color objects" in diagram (a). In the notation of visual variables, ordinary impression was displayed as gray dot, good impression was displayed as orange dot, bad impression was indicated as blue dot, and the number of observers was indicated by the size of the dot. Looking at Figure.3-left, the most common thing is finding color objects by "brightness", and the number of observers who recorded the "brightness" of bicycle is the largest. By rearranging the matrix in diagram (b), we found that the color objects can be divided into "gray", "white" and "yellow" (Figure.3-middle), there were many good impressions for "yellow and white (flowers)", and there were many bad impressions for "gray and white (street lights)" (Figure.3-right).

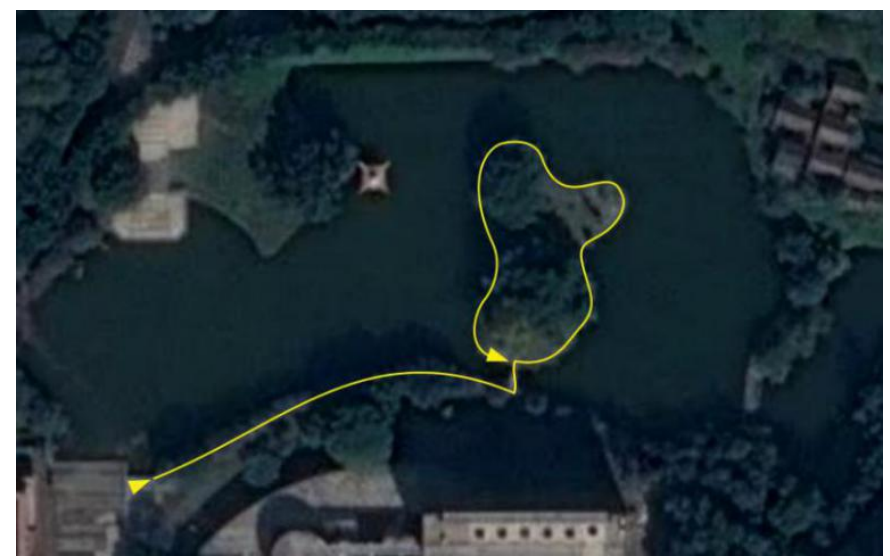

Figure 1. Natural lake and observation route in the campus of South China University of Technology 


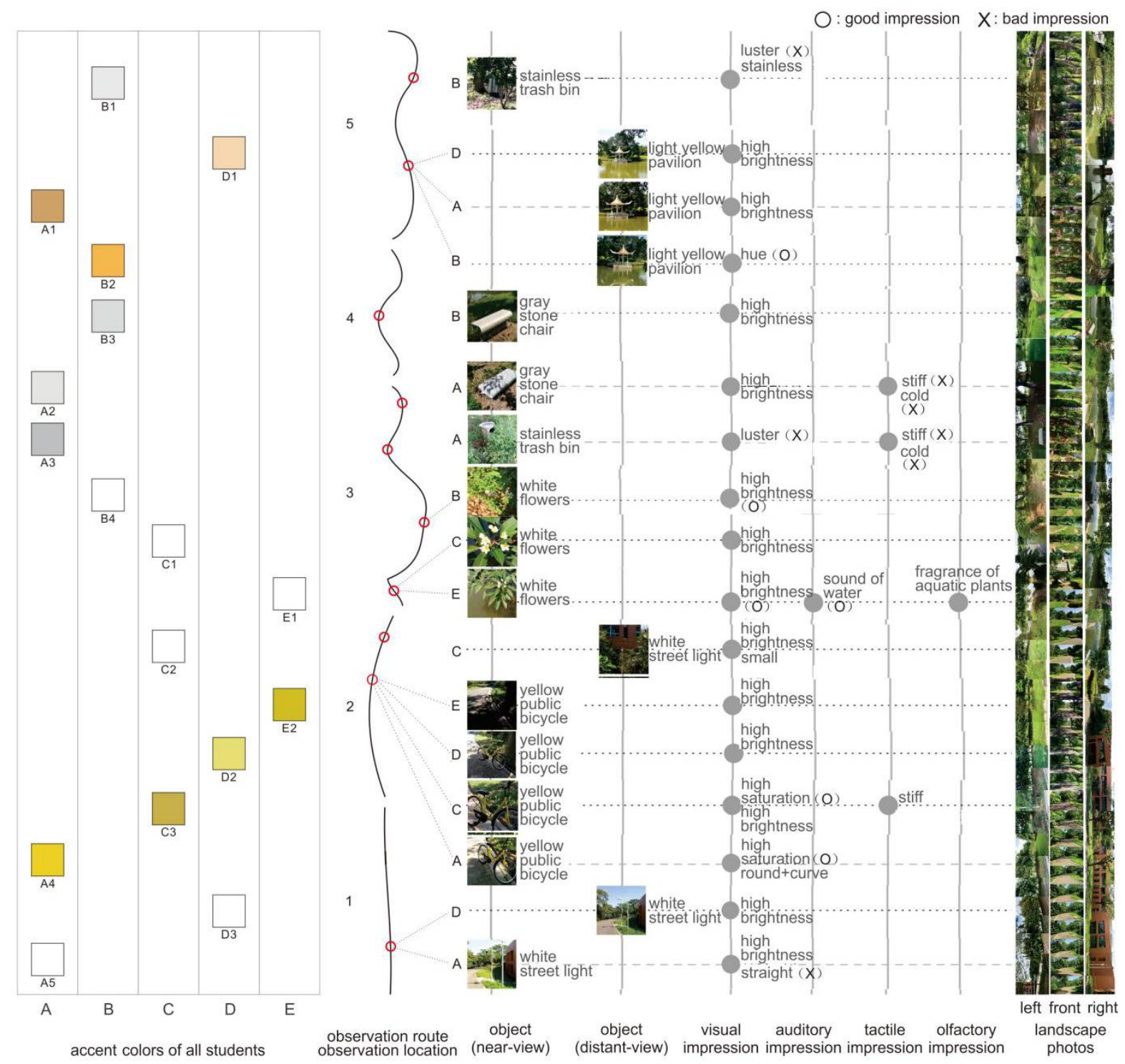

Figure 2. Diagram (a)

\begin{tabular}{|c|c|c|c|c|c|c|c|c|c|c|}
\hline $\begin{array}{l}\text { trash } \\
\text { bin(b) }\end{array}$ & & & & • & & & & & & \\
\hline pavilion & & & & 0 & & • & & & & \\
\hline $\begin{array}{l}\text { stone } \\
\text { chair(b) }\end{array}$ & & & & • & & & & & & \\
\hline $\begin{array}{l}\text { stone } \\
\text { chair(a) }\end{array}$ & & & & • & & & & - & - & \\
\hline $\begin{array}{l}\text { trash } \\
\text { bin(a) }\end{array}$ & & & & • & & & & - & - & \\
\hline $\begin{array}{l}\text { white } \\
\text { flowers(b) }\end{array}$ & & & & $\bullet$ & & & & & & \\
\hline $\begin{array}{l}\text { white } \\
\text { flowers(a) }\end{array}$ & & & & 8 & & & - & & & $\bullet$ \\
\hline $\begin{array}{l}\text { street } \\
\text { light(b) }\end{array}$ & & & & - & & & & & & \\
\hline $\begin{array}{l}\text { public } \\
\text { bicycle }\end{array}$ & & & $\bullet$ & 0 & ○ & & & - & & \\
\hline $\begin{array}{l}\text { street } \\
\text { light(a) }\end{array}$ & & - & $\bullet$ & 0 & & & & & & \\
\hline \multirow[t]{2}{*}{$\frac{\circ}{\frac{\circ}{0}}$} & \multirow[t]{2}{*}{ 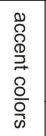 } & 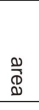 & $\begin{array}{l}\frac{\infty}{\vec{D}} \\
\frac{1}{0} \\
\end{array}$ & 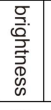 & 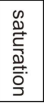 & $\overrightarrow{\vec{\sigma}^{\circ}}$ & \begin{tabular}{|l|} 
n \\
$o$ \\
c \\
å \\
\end{tabular} & $\stackrel{n}{\equiv}$ & $\frac{8}{2}$ & $\begin{array}{l}\stackrel{\infty}{3} \\
\stackrel{\underline{\Phi}}{=}\end{array}$ \\
\hline & & \multicolumn{5}{|c|}{ (1) } & WMAL & \multicolumn{2}{|c|}{ 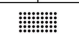 } & $\approx \approx$ \\
\hline
\end{tabular}
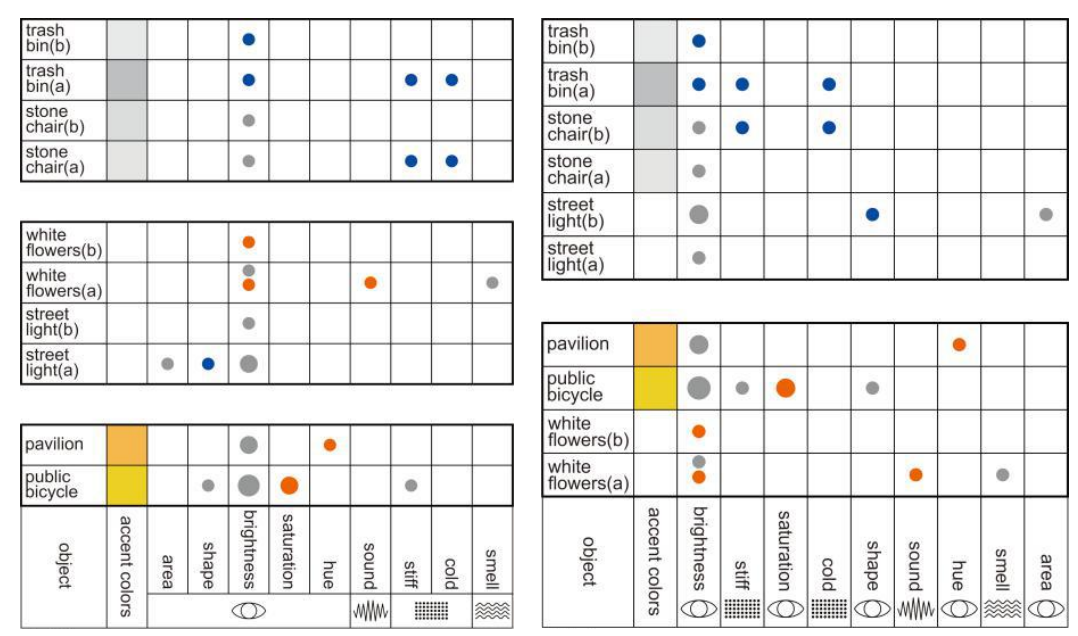

Notations: (D) visual

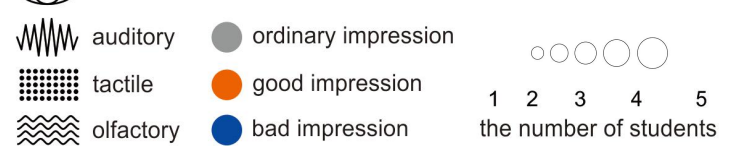

Figure 3. Diagram (b) 